\title{
Pengaruh Penambahan Serbuk Kaca Dan Abu Sekam Pada Tanah Lunak Berdasarkan Uji Konsolidasi
}

\author{
Dyah Pratiwi Kusumastuti ${ }^{1}$; Irma Sepriyanna ${ }^{2}$ \\ ${ }^{1,2}$ Program Studi Teknik Sipil, Sekolah Tinggi Teknik PLN \\ 11yah.pratiwi@sttpln.ac.id \\ 2irma.sepriyanna@sttpln.ac.id
}

\begin{abstract}
It can not be avoided when the construction must stand on soft soil, then the construction will suffer damage due to subsidence or congestion from soft soil. To improve soft soils as one part of the construction of them is the method of chemical stabilization of the soil. The stabilizer material mixed was $10 \%$ glass powder and the percentage of husk ash was $0 \%, 2.5 \%, 5 \%, 7.5 \%$ and $10 \%$ of the dry weight of the original soil sample. Changes in the characteristics of soft soil and stabilized soils are reviewed based on the consolidation test. Based on the results of the study, the value of the void ratio decreases with increasing glass dust and husk ash, where the lowest void ratio is 0.5328 obtained in the addition of $10 \%$ glass powder and $7.5 \%$ husk ash. A decrease in the void ratio indicates a decrease in the compression index $(C c)$ and the swelling index (Cs). The lowering of the compression index and the swelling index indicate that the addition of glass powder and husk ash causes the soft soil sample to become denser. The lowest compressive index and swelling index values were obtained in soil sample specimens with the addition of $10 \%$ glass powder and $10 \%$ husk ash, which respectively decreased by $35.165 \%$ and $75.757 \%$ when compared to the condition of the original soil sample.
\end{abstract}

Keywords: soft soil, glass powder, husk ash, consolidation

\begin{abstract}
ABSTRAK
Tidak dapat dihindari ketika konstruksi harus berdiri di atas tanah lunak, maka konstruksi tersebut akan mengalami kerusakan-kerusakan akibat penurunan atau kemampatan dari tanah lunak. Untuk memperbaiki sifat tanah lunak sebagai salah satu bagian dari konstruksi diantaranya adalah dengan metode stabilisasi tanah secara kimiawi. Bahan stabilator yang dicampur adalah $10 \%$ serbuk kaca dan prosentase abu sekam 0\%, 2,5\%, 5\%, 7,5\% dan 10\% terhadap berat kering dari contoh tanah asli. Perubahan karakteristik tanah asli dan tanah distabilisasi ditinjau berdasarkan pengujian konsolidasi. Berdasarkan hasil penelitian didapat nilai angka pori semakin menurun seiring dengan bertambahnya serbuk kaca dan abu sekam, dimana angka pori terendah sebesar 0,5328 yang didapat pada penambahan $10 \%$ serbuk kaca dan 7,5\% abu sekam. Menurunnya nilai angka pori menunjukkan semakin menurunnya indeks pemampatan $\left(C_{c}\right)$ dan indeks mengembang $\left(C_{s}\right)$. Semakin menurunnya indeks pemampatan dan indeks mengembang menandakan bahwa dengan penambahan serbuk kaca dan abu sekam menyebabkan contoh tanah lunak menjadi semakin padat. Nilai indeks pemampatan dan indeks mengembang terendah didapat pada benda uji contoh tanah dengan penambahan 10\% serbuk kaca dan 10\% abu sekam, yang masing-masing mengalami penurunan sebesar 35,165\% dan 75,757\% bila dibandingkan pada kondisi contoh tanah asli.
\end{abstract}

Kata kunci: tanah lunak, serbuk kaca, abu sekam, konsolidasi 


\section{PENDAHULUAN}

Sekitar 20 juta hektar atau lebih dari 10\% luas daratan di Indonesia merupakan tanah lunak yang terdiri dari tanah lempung lunak dan tanah gambut [1]. Tanah lunak sendiri memiliki sifat gaya geser yang kecil, kemampatan besar, koefisien permeabilitas kecil dan daya dukung rendah [2]. Tanah sendiri sangat penting dalam pekerjaan konstruksi, karena tanah akan menerima beban yang berada diatasnya. Kriteria tanah yang baik untuk keperluan dalam pembangunan konstruksi yaitu apabila terjadi penurunan tidak melebihi dari syarat angka yang diijinkan dan memiliki daya dukung tanah yang baik [3].

Hal yang sering terjadi pada suatu konstruksi berdiri di atas tanah lunak adalah konstruksi tersebut akan mengalami kerusakan-kerusakan seperti retak atau runtuh akibat penurunan atau kemampatan dari tanah lunak. Penurunan yang terjadi pada tanah lunak, tidak hanya penurunan segera yang terjadi akibat pembebanan seketika tetapi juga penurunan yang disebabkan oleh proses konsolidasi. Ada dua masalah yang dihadapi dalam proses konsolidasi pada tanah lunak, yaitu besarnya penurunan dan jangka waktu yang diperlukan untuk mencapai penurunan maksimum berlangsung dalam waktu yang cukup lama [4].

Untuk memperbaiki sifat tanah lunak agar memenuhi persyaratan sebagai salah satu bagian dari konstruksi diantaranya adalah dengan metode stabilisasi tanah. Stabilisasi tanah dapat didefinisikan sebagai suatu usaha untuk merubah atau memperbaiki sifat-sifat teknis tanah agar memenuhi persyaratan teknis tertentu (Hardiyatmo, 2010 dalam Setyadi, 2019). Metode stabilisasi yang banyak digunakan pada penelitian-penelitian sebelumnya, terkait perbaikan tanah lunak adalah metode stabilisasi kimiawi. Stabilisasi kimiawi adalah perbaikan tanah dengan membubuhkan atau mencampurkan bahan kimia [6], menambahkan bahan aditif, bahan kimia atau bahan limbah yang tidak terpakai [3] ke dalam tanah asli.

Penelitian sebelumnya didapatkan parameter hasil uji konsolidasi tanah lempung dengan penambahan limbah gypsum dan semen sebagai bahan stabilisasi mengalami peningkatan yang cukup besar, dimana nilai koefisien konsolidasi tanah asli sebesar $0,0318 \mathrm{~cm}^{2} /$ detik sedangkan tanah dengan penambahan gypsum sebesar $0,0519 \mathrm{~cm}^{2} /$ detik dan tanah dengan penambahan semen sebesar $0,0588 \mathrm{~cm}^{2} /$ detik [7]. Perbaikan tanah lempung dengan bahan tambah, khususnya campuran abu sekam padi antara $1 \%$ sampai $2 \%$ dan penambahan pasir antara $10 \%$ dan $20 \%$ secara umum dapat meningkatkan daya dukung tanah, memperkecil penurunan lapisan tanah dan potensi pengembangan tanah $[8]$.

Penelitian lainnya menyatakan angka pori pada tanah lunak cenderung mengalami penurunan seiring dengan penambahan serbuk kaca dan serat karung plastik [9]. Persentase campuran limbah plafon gypsum menyebabkan berkurangnya angka pori pada tanah lempung ekspansif dan pencampuran $15 \%$ limbah plafon gypsum pada tanah lempung ekspansif dapat menurunkan indeks pemampatan yang didapat dari pengujian konsolidasi [3].

Berdasarkan penelitian sebelumnya, maka pada penelitian ini akan menggunakan bahan stabilisasi serbuk kaca dan abu sekam (abu gosok) untuk memperbaiki sifat teknis tanah lunak ditinjau dari parameter pengujian konsolidasi. Pemilihan serbuk kaca dan abu sekam sebagai stabilator pada penelitian ini sebagai upaya pemanfaatan limbah kaca yang banyak ditemui dan diharapkan mampu meningkatkan nilai ekonomi dari abu sekam (abu gosok).

\section{METODE/PERANCANGAN PENELITIAN}

Penelitian yang dilakukan merupakan skala laboratorium, dimana pelaksanaan penelitian mayoritas dilakukan di dalam laboratorium Mekanika Tanah, Departemen Sipil, Sekolah Tinggi Teknik PLN. Tahap persiapan diawali dengan pengambilan contoh tanah di daerah Duri Kosambi, 


\section{JURNAL FORUM MEKANIIKA}

Vol. 8, No. 2, November 2019, P-ISSN: 2356-1491, E-ISSN: 2655-8211

DOI: https://doi.org/10.33322/forummekanika.v8i2.882

Cengkareng, Jakarta Barat. Contoh tanah yang digunakan dalam penelitian merupakan contoh tanah terganggu yang diambil pada kedalaman $20-100 \mathrm{~cm}$.

Bahan stabilator yang digunakan dan dicampur ke dalam contoh tanah asli adalah $10 \%$ serbuk kaca dan variasi penambahan abu sekam. Prosentase abu sekam yang ditambahkan yaitu 0\%, 2,5\%, $5 \%, 7,5 \%$ dan $10 \%$ terhadap berat kering dari contoh tanah asli. Benda uji yang dibuat untuk masingmasing variasi penambahan bahan stabilator sebanyak 3 buah benda uji.

Penelitian diawali dengan pengujian analisis saringan, hydrometer dan batas konsistensi untuk menentukan jenis contoh tanah asli berdasarkan sistem klasifikasi USCS. Tahapan pengujian selanjutnya adalah pengujian konsolidasi dengan menggunakan alat oedometer. Pengujian konsolidasi dilakukan terhadap contoh tanah asli maupun contoh tanah asli dengan penambahan bahan stabilator. Pada pengujian konsolidasi, penerapan beban yang diberikan kepada benda uji adalah $0,5 \mathrm{~kg}, 1 \mathrm{~kg}, 2 \mathrm{~kg}, 4 \mathrm{~kg}, 8 \mathrm{~kg}$ dan $16 \mathrm{~kg}$ yang diamati masing-masing beban selama $24 \mathrm{jam}$, untuk kemudian dilakukan pengurangan beban mulai $8 \mathrm{~kg}$ dan $4 \mathrm{~kg}$ dengan pembacaan selama 6 jam.

Dari hasil pengujian konsolidasi akan didapatkan nilai perubahan angka pori, koefisien pemampatan $\left(a_{v}\right)$, indeks pemampatan $\left(C_{c}\right)$ dan nilai indeks mengembang $\left(C_{s}\right)$. Hasil pengujian konsolidasi tersebut digunakan untuk melihat pengaruh penambahan bahan stabilator serbuk kaca dan abu sekam ke dalam tanah lunak terhadap parameter konsolidasi.

\section{HASIL DAN PEMBAHASAN}

\subsection{Klasifikasi Tanah}

Berdasarkan hasil analisis saringan dan hydrometer contoh tanah asli didapat kandungan pasir sebesar $21,716 \%$, kandungan lanau sebesar 25,583\% dan kandungan lempung 52,101\%. Untuk nilai batas konsistensi [10] pada contoh tanah asli didapatkan nilai batas cair (LL) sebesar 72,878\% dan nilai batas plastis (PL) sebesar 61,544\%., sehingga nilai indeks plastisitas (IP) sebesar 11,334\%. Berdasarkan hasil analisis saringan, hydrometer dan batas konsistensi contoh tanah asli, kemudian dilakukan klasifikasi menggunakan sistem Unified Soil Classification System (USCS), sehingga diperoleh hasil klasifikasi contoh tanah asli adalalah $\mathrm{MH}$ atau $\mathrm{OH}$ (lanau atau tanah organic dengan plastisitas tinggi).

\subsection{Hasil Pengujian Konsolidasi}

Pengujian konsolidasi pada penelitian ini bertujuan untuk mendapatkan perubahan nilai angka pori, koefisien pemampatan, nilai indeks pemampatan dan nilai indeks mengembang pada contoh tanah asli maupun contoh tanah dengan penambahan bahan stabilator. Hasil perubahan angka pori, koefisien pemampatan, nilai indeks pemampatan dan nilai indeks mengembang contoh tanah asli dan contoh tanah distabilisasi dapat dilihat pada Gambar 1 sampai Gambar 4 sebagai berikut: 


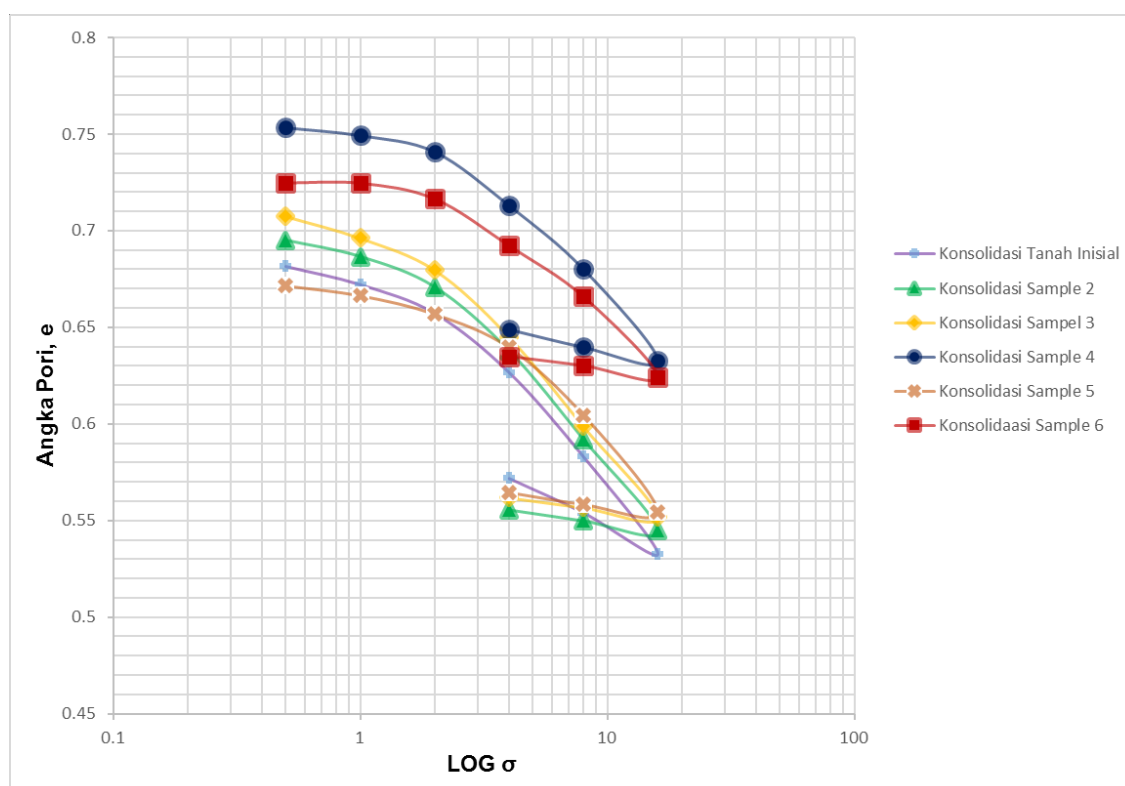

Gambar 1. Hubungan angka pori dengan tegangan dalam fungsi log pada contoh tanah asli dengan penambahan serbuk kaca dan variasi abu sekam

Berdasarkan Gambar 1 terlihat perubahan angka pori, semakin banyak variasi penambahan bahan stabilator maka angka pori semakin mengalami kenaikan. Hal ini disebabkan butiran tanah yang awalnya merupakan tanah kohesif dan berbutir halus menjadi lebih berbutir. Pada tanah distabilisasi abu sekam dan serbuk kaca, angka pori terkecil terdapat pada penambahan $2,5 \%$ abu sekam $+10 \%$ serbuk kaca dengan penerapan beban $16 \mathrm{~kg}$ yaitu 0,5518 . Untuk kemudian mengalami peningkatan,dimana angka pori terbesar terdapat pada penambahan $5 \%$ abu sekam $+10 \%$ serbuk kaca dengan penerapan beban $16 \mathrm{~kg}$ yaitu 0,6327 . Penurunan angka pori disebabkan ruang pori yang berada diantara butiran-butiran tanah terisi oleh serbuk kaca dan [11] menyatakan semakin kecil nilai angka pori maka semakin padat tanahnya.

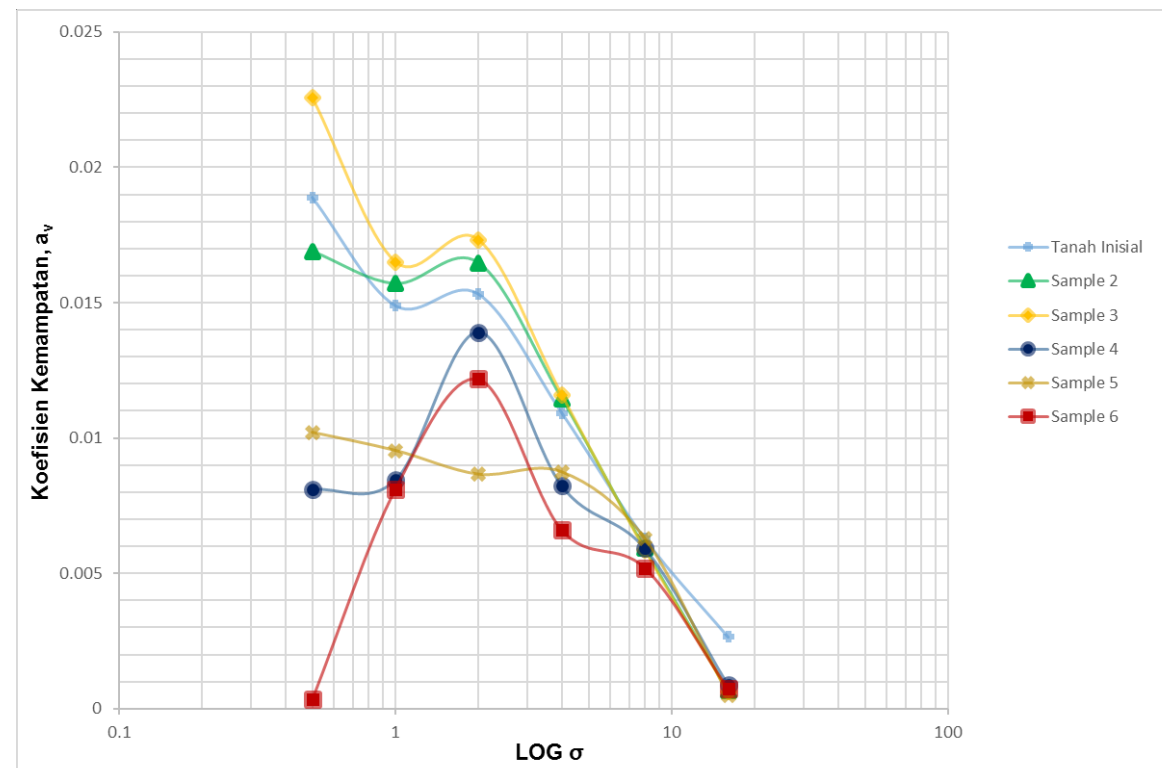

Gambar 2. Hubungan koefisien pemampatan dengan tegangan dalam fungsi log pada contoh tanah asli dengan penambahan serbuk kaca dan variasi abu sekam 
Berdasarkan Gambar 2, koefisien Kemampatan terbesar terdapat pada penambahan 2,5\% abu sekam $+10 \%$ serbuk kaca dengan penerapan beban 0,5 kg dibandingkan dengan koefisien pemampatan tanah inisial. Hal ini dapat didefinisikan bahwa perubahan angka pori terbesar akibat penambahan beban terdapat pada penambahan $2,5 \%$ abu sekam $+10 \%$ serbuk kaca, yaitu sebesar $0,0226 \mathrm{~cm} 2 / \mathrm{kg}$. Untuk kemudian perubahan angka pori semakin menurun seiring dengan bertambahnya beban yang diterapkan. Perubahan angka pori terkecil terjadi pada penerapan beban $16 \mathrm{~kg}$ yang terdapat pada penambahan $7,5 \%$ abu sekam $+10 \%$ serbuk kaca, yaitu $0,0005 \mathrm{~cm} 2 / \mathrm{kg}$.

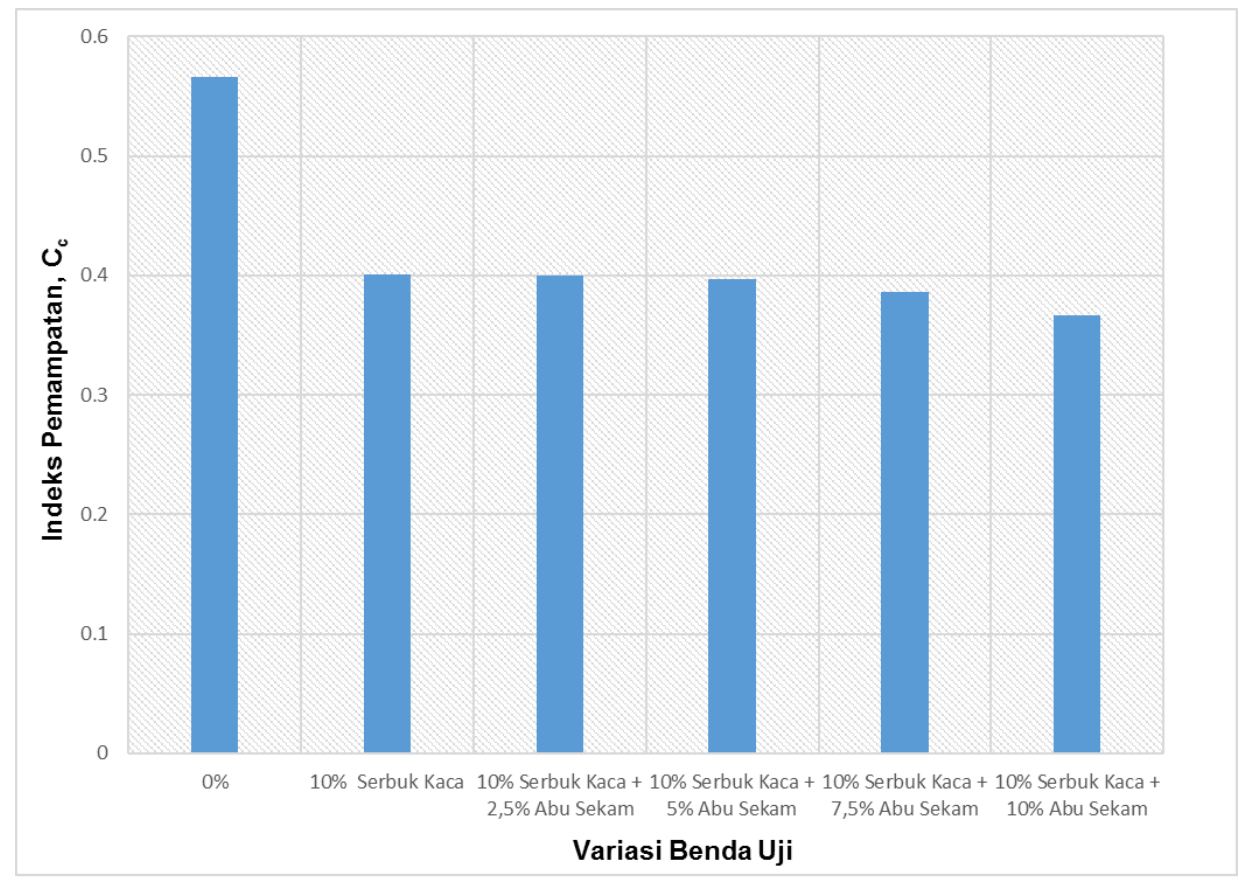

Gambar 3. Perubahan nilai indeks pemampatan $\left(\mathrm{C}_{\mathrm{c}}\right)$ berdasarkan variasi benda uji

Berdasarkan Gambar 3, dapat dilihat bahwa semakin banyak penambahan bahan stabilator pada contoh tanah asli maka indeks pemampatan dari hasil uji konsolidasi semakin menurun. Nilai indeks pemampatan terendah didapat pada variasi penambahan $10 \%$ serbuk kaca dan $10 \%$ abu sekam sebesar 0,3669 atau mengalami penurunan sebesar 35,165\% dibandingkan indeks pemampatan tanah asli. Semakin menurunannya indeks pemampatan seiring dengan semakin padatnya contoh tanah distabilisasi dan rongga pori tanah terisi oleh butiran bahan stabilator. 


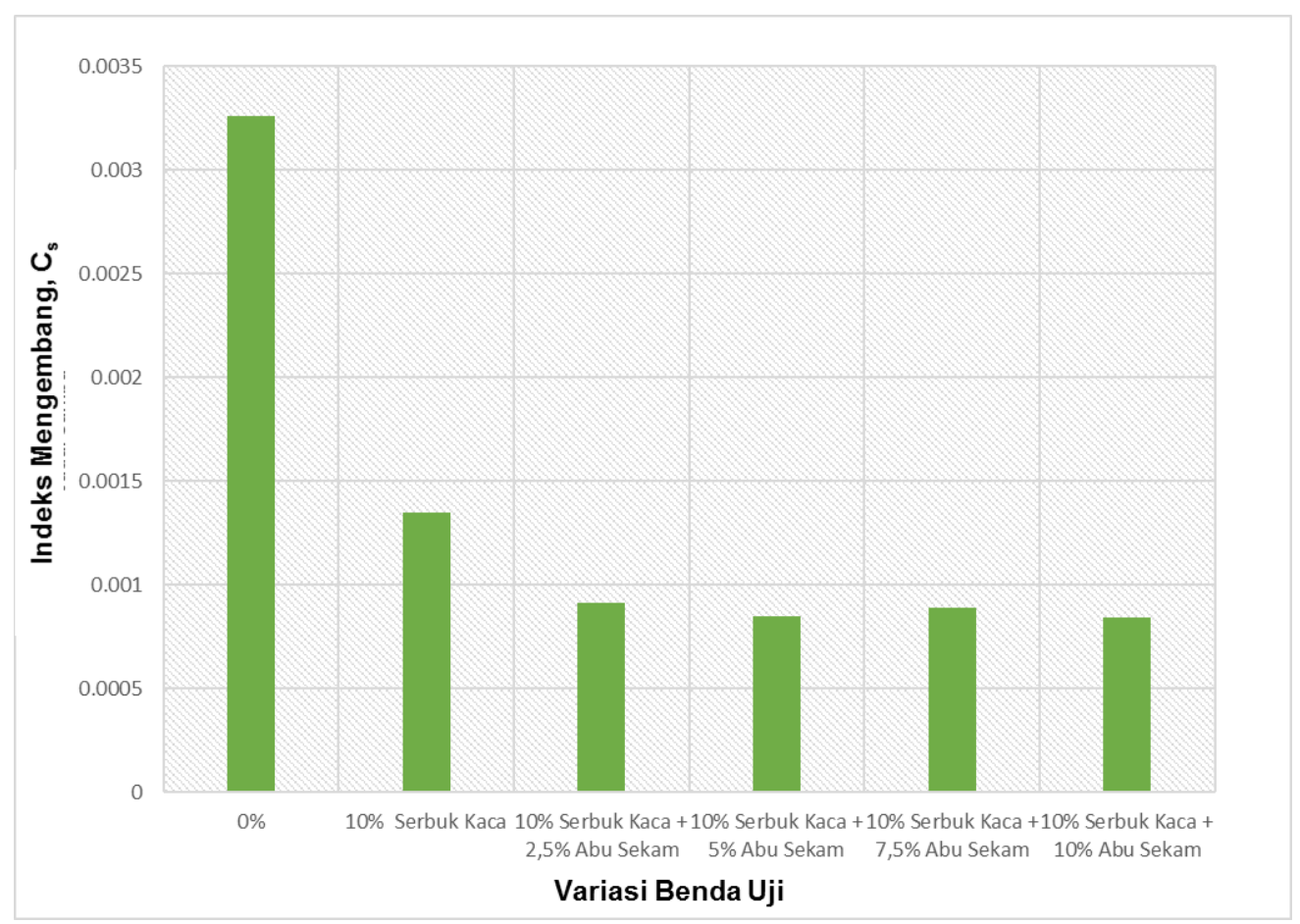

Gambar 4. Perubahan nilai indeks mengembang $\left(\mathrm{C}_{\mathrm{s}}\right)$ berdasarkan variasi benda uji

Indeks mengembang didapatkan dari perubahan angka pori pada saat proses pengurangan beban bertahap ketika pengujian konsolidasi. Berdasarkan Gambar 4, dapat dilihat bahwa semakin banyak penambahan bahan stabilator pada contoh tanah asli maka indeks mengembang dari hasil uji konsolidasi semakin menurun. Nilai indeks mengembang terendah didapat pada variasi penambahan $10 \%$ serbuk kaca dan $10 \%$ abu sekam sebesar 0,0008 atau mengalami penurunan sebesar 75,757\% dibandingkan indeks mengembang tanah asli. Semakin bertambahnya penambahan bahan stabilator pada contoh tanah asli, maka potensi mengembang dari tanah asli semakin kecil.

\subsection{Perbandingan Indeks Mengembang dan Angka Pori}




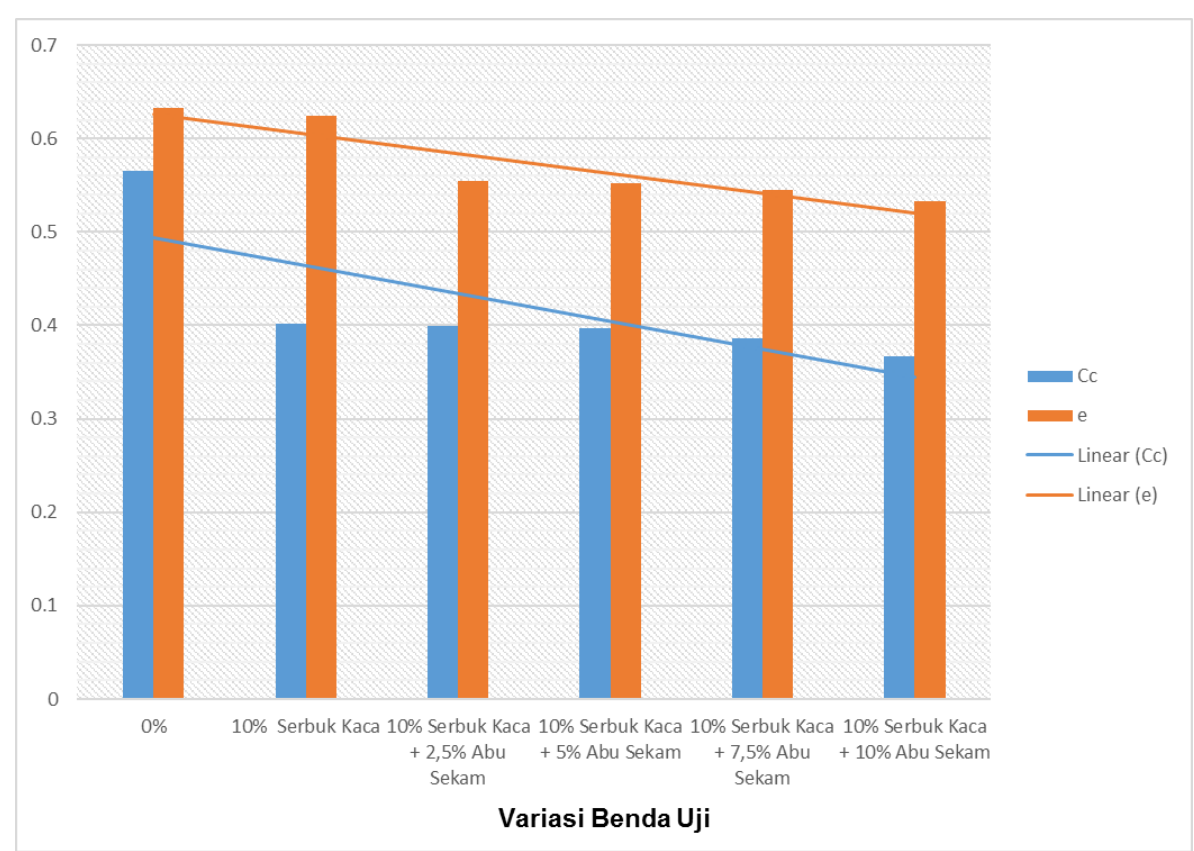

Gambar 5. Perbandingan nilai angka pori pada pembebanan $16 \mathrm{~kg}$ dan indeks pemampatan $\left(\mathrm{C}_{\mathrm{c}}\right)$ berdasarkan variasi benda uji

Gambar 5 menunjukkan perbandingan antara nilai angka pori ketika penerapan beban $16 \mathrm{~kg}$ dan indeks mengembang $\left(\mathrm{C}_{\mathrm{c}}\right)$ pada saat pengujian konsolidasi terhadap variasi penambahan bahan stabilator. Berdasarkan perbandingan tersebut dapat dilihat bahwa penurunan indeks pemampatan seiring dengan menurunnya angka pori. Semakin kecil nilai angka pori maka semakin menurun indeks pemampatan dari benda uji, dimana nilai angka pori dan indeks pemampatan terendah terdapat pada contoh tanah asli dengan penambahan $10 \%$ serbuk kaca dan $10 \%$ abu sekam. Hal ini disebabkan butiran-butiran halus bahan stabilator mampu mengisi ruang pori diantara butiran tanah. Tingkat kepadatan tanah juga semakin meningkat seiring dengan bertambahnya bahan stabilator, hal ini terlihat dari semakin kecilnya rentang indeks pemampatan diantara benda uji yang mengalami perlakuan.

\section{KESIMPULAN DAN SARAN}

Kesimpulan yang dapat diambil pada penelitian ini yaitu nilai angka pori semakin menurun seiring dengan bertambahnya serbuk kaca dan abu sekam, dimana angka pori terendah sebesar 0,5328 yang didapat pada penambahan $10 \%$ serbuk kaca dan 7,5\% abu sekam. Menurunnya nilai angka pori menunjukkan semakin menurunnya indeks pemampatan $\left(\mathrm{C}_{\mathrm{c}}\right)$ dan indeks mengembang $\left(\mathrm{C}_{\mathrm{s}}\right)$. Semakin menurunnya indeks pemampatan dan indeks mengembang menandakan bahwa dengan penambahan serbuk kaca dan abu sekam menyebabkan contoh tanah lunak menjadi semakin padat. Nilai indeks pemampatan dan indeks megembang terendah didapat pada benda uji contoh tanah dengan penambahan $10 \%$ serbuk kaca dan $10 \%$ abu sekam, yang masing-masing mengalami penurunan sebesar 35,165\% dan 75,757\% bila dibandingkan pada kondisi contoh tanah asli.

Sebagai salah satu bahan konstruksi, maka tanah distabilisasi serbuk kaca dan abu sekam perlu dilakukan pengujian lebih lanjut mengenai besarnya penurunan yang terjadi, baik penurunan seketika maupun penurunan akibat proses konsolidasi. Dimana proses analisis penurunannya didasarkan pada data konstruksi yang digunakan. Selain itu, jika tanah akan digunakan sebagai tanah dasar maka perlu ada penelitian lebih lanjut mengenai daya dukung tanah dengan menggunakan metode CBR. 


\section{UCAPAN TERIMAKASIH}

Ucapan terima kasih kepada Kemenristekdikti untuk bantuan dana Hibah Dikti melalui Skema Penelitian Dosen Pemula 2019, terima kasih kepada Ketua dan Lembaga Penelitian dan Pengabdian Masyarakat (LPPM) dari Sekolah Tinggi Teknik PLN dan semua pihak yang telah membantu penelitian ini.

\section{DAFTAR PUSTAKA}

[1] W. P. Kuswanda, "Perbaikan Tanah Lempung Lunak Metoda Preloading Pada Pembangunan Infrastruktur Transportasi Di Pulau Kalimantan,” in Prosiding Seminar Nasional Geoteknik, 2016, pp. 188-207.

[2] N. Shafira, Y. Zaika, and E. A. Suryo, "Pengaruh Waktu Perawatan (Curing) Pada Tanah Campuran Semen Portland Tipe I Terhadap Karakteristik Tanah Lunak Di Proyek Jalan Tol Gempol - Pasuruan,” J. Mhs. Jur. Tek. Sipil Univ. Brawijaya, vol. 1, no. 3, 2018, doi: 10.1017/CBO9781107415324.004.

[3] R. Dewi, Y. Sutejo, R. Rahmadini, M. Arfan, and R. K. Rustam, "Pengaruh Limbah Plafon Gipsum Terhadap Penurunan Konsolidasi Pada Tanah Lempung Ekspansif," Cantilever, vol. 8, no. 1, pp. 1-7, 2019, doi: 10.35139/cantilever.v8i1.78.

[4] T. N. Luntungan, J. E. . Sumampouw, and S. Rondonuwu, "Analisis Konsolidasi Tanah Di Bawah Bendungan Dengan Menggunakan Metode Akar Waktu Dan Metode Hyperbola," Sipil Statik, vol. 7, no. 4, pp. 389-396, 2019.

[5] V. A. U. R. Setyadi, "Sifat Mekanis Tanah Lempung Lunak Artifisial Untuk Infrastruktur dengan Beban Lalu Lintas Rendah,” Politeknologi, vol. 18, no. 1, pp. 85-92, 2019.

[6] Rudiansyah, "Studi Karakteristik Tanah Lempung Lunak Akibat Adanya Penambahan Material Limbah,” Jukung J. Tek. Lingkung., vol. 4, no. 1, pp. 39-49, 2018.

[7] Maryati; Yayuk Apriyanti, "Analisis Perbandingan Penggunaan Limbah Gypsum Dengan Semen Sebagai Bahan Stabilisasi Tanah Lempung," Fropil, vol. 4, no. 1, pp. 49-64, 2016.

[8] M. Ludfian, "Stabilisasi Tanah Lempung Menggunakan Campuran Limbah Abu Sekam Padi dan Pasir dengan Metode Pemadatan Laboratorium," E-Journal Pendidik. Tek. Sipil dan Perenc., vol. 5, no. 6, 2017.

[9] D. P. Kusumastuti, I. Sepriyanna, and Hastanto, "Dengan Serbuk Kaca Dan Serat Karung Plastik," Semnastek, pp. 1-10, 2018.

[10] I. Kusumastuti, Dyah Pratiwi; Sepriyanna, "Soft Soil Stabilization With Rice Husk Ash and Glass Powder Based on Physical Characteristics," in IOP Conference Series: Materials Science and Engineering, 2019, pp. 1-6, doi: https://doi.org/10.1088/1757899X/650/1/012025.

[11] Kukuh Prihatin, "Pengaruh Penambahan Fly Ash Pada Tanah Lempung Terhadap Parameter Konsolidasi,” J. Inersia, vol. VII, no. 1, pp. 1-10, 2015. 